\title{
bcl-x, a bcl-2-Related Gene That Functions as a Dominant Regulator of Apoptotic Cell Death
}

\author{
Lawrence H. Boise, * Maribel González-Garcia, \\ and Craig $\mathbf{B}$. Thompson * \\ *Howard Hughes Medical Institute \\ Departments of Medicine \\ and Molecular Genetics and Cell Biology \\ University of Chicago \\ Chicago, Illinois 60637 \\ tDepartment of Pathology \\ fDepartment of Medicine \\ University of Michigan Medical School \\ Ann Arbor, Michigan 48109
} Christina E. Postema, * Liyun Ding,† Tullia Lindsten, * Laurence A. Turka, $¥$ Xiaohong Mao," Gabriel Nuñez, $†$

\section{Summary}

We report the isolation of bcl-x, a bcl-2-related gene that can function as a bcl-2-independent regulator of programed cell death (apoptosis). Alternative splicing results in two distinct bcl-x mRNAs. The protein product of the larger mRNA, bcl- $x_{L}$, is similar in size and predicted structure to Bcl-2. When stably transfected into an IL-3-dependent cell line, bc/- $\mathrm{x}_{\mathrm{L}}$ inhibits cell death upon growth factor withdrawal at least as well as bcl-2. Surprisingly, the second mRNA species, bcl- $x_{\mathrm{s}}$, encodes a protein that inhibits the ability of bcl-2 to enhance the survival of growth factor-deprived cells. In vivo, bcl- $x_{s}$ mRNA is expressed at high levels in cells that undergo a high rate of turnover, such as developing lymphocytes. In contrast, bcl- $x_{L}$ is found in tissues containing long-lived postmitotic cells, such as adult brain. Together these data suggest that bcl-x plays an important role in both positive and negative regulation of programed cell death.

\section{Introduction}

The control of cell number in multicellular eukaryotes represents a balance between cell proliferation and cell death. Although a great deal has been learned in recent years about the regulation of cell proliferation, relatively little is known about the regulation of cell death (for reviews see Ellis et al., 1991; Raff, 1992). Recently, attention has begun to focus on the mechanisms that regulate programed cell death (apoptosis) (Williams, 1991). Apoptosis is an active process by which many cells dle during development and self-maintenance in complex eukaryotes (Kerr et al., 1972). Cell death by apoptosis occurs when a cell activates an internally encoded suicide program as a result of either extrinsic or intrinsic signals. Apoptotic cell death is characterized by plasma membrane blebbing, cell volume loss, nuclear condensation, and endonucleolytic degradation of DNA at nucleosomal intervals (Wyllie et al., 1980).

Two of the best-studied vertebrate systems in which programed cell death plays a role are neural and lymphoid development. During T cell development in the thymus, each individual $T$ cell precursor generates a unique $T$ cell antigen receptor by combinatorial rearrangement of $T$ cell antigen receptor gene segments, and the cell subsequently undergoes a series of selection processes (for reviews see Blackman et al., 1990; Rothenberg, 1992). T cells expressing autoreactive $T$ cell antigen receptors are deleted by apoptosis as a result of negative selection (Murphy et al., 1990). Other cells undergo positive selection through interaction with self-encoded major histocompatibility complex molecules expressed on thymic stromal cells, a process that prevents programed cell death and results in the subsequent major histocompatibility complex restriction of the mature $T$ cell repertoire. An additional set of thymic cells are thought to die as a result of neglect, the absence of either negative or positive selection. Extensive cell death also occurs in the developing nervous system (for reviews see Cowan et al., 1984; Davies, 1987; Oppenheim, 1991). Following an initial expansion of neurons during development, a significant reshaping of neural structures occurs as a result of the establishment of synaptic interactions. During this reshaping period, the survival of neurons appears to be determined by their supply of neurotrophic growth factors. Cells that become growth factor deficient die by apoptosis. Once synaptic connections are established, the surviving neurons develop into postmitotic cells with extended life spans. Thus, programed cell death plays an essential role in lymphoid development by removing autoreactive T cells and within the nervous system by facilitating the establishment of effective synaptic networks.

Because of the importance of programed cell death to these developmental processes, considerable interest has arisen in genes that are capable of regulating apoptosis. One of the most important advances in our understanding of the regulation of apoptotic cell death in vertebrates has come from studies of the oncogene $\mathrm{bcl}-2$. bcl-2 was originally cloned from the breakpoint of a $(14 ; 18)$ translocation present in many human $B$ cell lymphomas (Cleary et al., 1986; Tsujimoto and Croce, 1986). This translocation results in the deregulated expression of the bcl-2 gene as a result of its juxtaposition with the immunoglobulin heavy chain gene locus (Bakhshi et al., 1985). In vitro, bcl-2 has been shown to prevent apoptotic cell death in cultured cells that are deprived of growth factors (Vaux et al., 1988; Hockenbery et al., 1990; Nuñez et al., 1990; Borzillo et al., 1992; Garcia et al., 1992). However, bcl-2 is not able to block apoptosis in all cells induced by cytokine deprivation or receptor-mediated signaling. For example, bcl-2 prevents apoptosis in hematopoietic cell lines dependent on interleukin-3 (IL-3), IL-4, or granulocyte macrophage colony-stimulating factor, but it fails to prevent apoptosis in other cell lines following IL-2 or IL-6 deprivation (Nuñez et al., 1990). Overexpression of bcl-2 also fails to prevent antigen receptor-induced apoptosis in some B cell lines (Cuende et al., 1993). In vivo, bcl-2 prevents many, but not all, forms of apoptotic cell death that occur during 
lymphoid (Sentman et al., 1991; Strasser et al., 1991a, 1991b; Siegel et al., 1992) and neural (Allsop et al., 1993) development. Expression of a bcl-2 transgene can prevent radiation- and calcium ionophore-induced apoptotic cell death in thymocytes but does not inhibit the process of negative selection (Sentman et al., 1991; Strasser et al., 1991a). Similarly, overexpression of $b c /-2$ can prevent apoptosis in neurons dependent on nerve growth factor but not neurons dependent upon ciliary neurotrophic factor (Allsop et al., 1993). These results suggest the existence of multiple independent intracellular mechanisms of apoptosis, some of which can be prevented by bcl-2 and others of which are unaffected by this gene. Alternatively, these additional pathways may involve proteins that differentially regulate $b c l-2$ function.

Our interest in apoptosis arose as a result of our studies characterizing avian lymphoid development and programed cell death in the chicken bursa of Fabricius and thymus. In an initial series of studies, we used low stringency hybridization with a murine bc/-2 cDNA probe in an attempt to identify bcl-2-related genes in chicken lymphoid cells. One of the clones we isolated, $b c l-x$, contains an open reading frame that displayed $44 \%$ amino acid identity with human or mouse $b c /-2$. Southern blotting revealed that chicken $b c /-x$ is encoded by a gene that is distinct from chicken $b c l-2$. Chicken $b c l-x$ was subsequently used to isolate two distinct cDNAs derived from the human $b c l-x$ gene. These two cDNAs differ in their predicted open reading frames. One CDNA, bcl- $x_{L}$, contains an open reading frame with 233 amino acids with similar domains to those previously described for $b c /-2$. The other cDNA, $b c /-x_{S}$, encodes a 170 amino acid protein in which the region of highest homology to $b c l-2$ has been deleted. The difference in these two cDNAs arises from differential usage of two $5^{\prime}$ splice sites within the first coding exon. When the ability of these two proteins to regulate apoptotic cell death was compared, it was found that $b c /-x_{L}$ rendered cells resistant to apoptotic cell death upon growth factor deprivation, while $b c / x_{s}$ could prevent overexpression of bcl-2 from inducing resistance to apoptotic cell death. Thus, it appears that the regulation of both expression and splicing of $b c /-x$ during development may play a critical role in determining the susceptibility of cells to programed cell death. Consistent with this hypothesis, we have found that immature thymocytes that are in the process of undergoing selection in the thymus express a high level of $b c l-x_{S}$ message. The expression of $b c /-x_{S}$ could potentially account for the inability of $b c l-2$ to prevent death by negative selection in this cell population. $b c l-x_{S}$ can function as a dominant regulator of cell death even in the presence of high level $b c l-2$ expression. In addition, we have found that mature neural structures constitutively express only the $b c /-x_{L}$ mRNA. Thus, $b c /-x_{L}$ may contribute to the resistance to programed cell death and long-term viability of this important postmitotic cell population. Together, our studies suggest that the two bcl-x gene products may regulate one or more bcl-2-dependent or bcl-2-independent pathways of apoptotic cell death.

\section{Results}

\section{Cloning of $\mathbf{b c l}-\mathbf{x}$}

Avian lymphocytes develop in two distinct organs, the bursa of Fabricius and the thymus. $B$ and T cells devel-

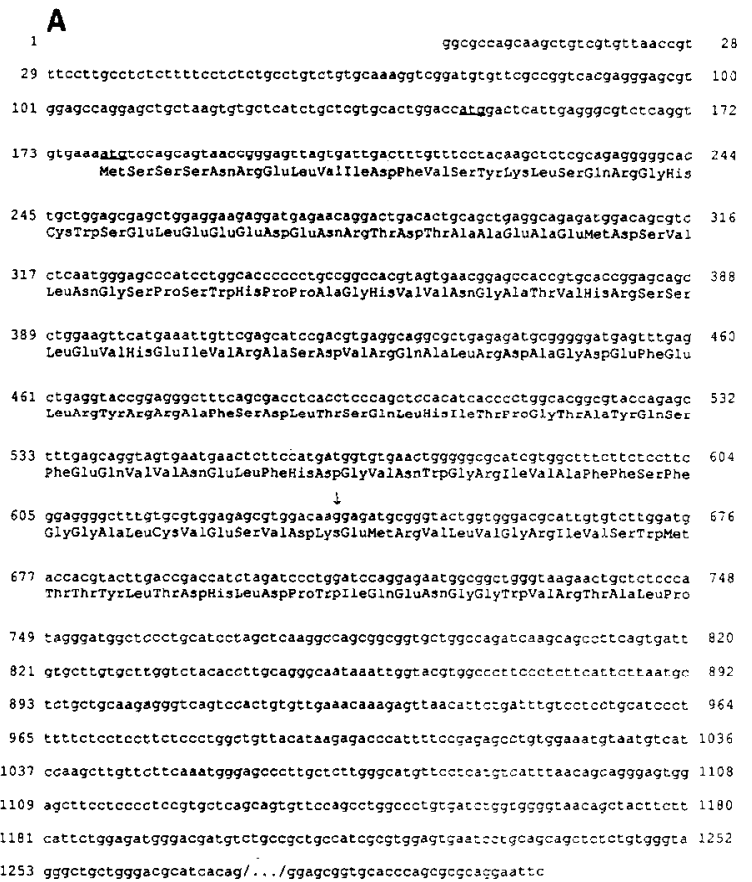

\section{B}

$$
\begin{aligned}
& \text { be } 1-x \quad 1 \text {,....MSSSNRELVIDEVSYKLSORGHCWSELEEEDENRTDTAAEAEMD } 44
\end{aligned}
$$

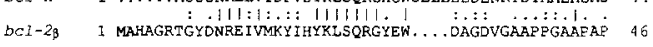

$$
\begin{aligned}
& \text { be1-x } 45 \text { SVLNGSP SWHPEAGHWNGATVHRSSLEVHEIVRASD.........VRQ } 84
\end{aligned}
$$

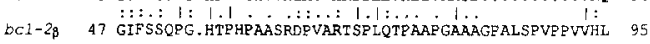

$$
\begin{aligned}
& \text { bCI-x } 85 \text { ALRDAGDEEELRYRRAF SDLTSOLHITPGTAYOSEEOVVNELEHDGVNWG } 134
\end{aligned}
$$

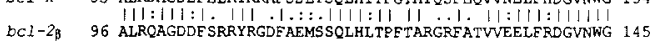

$$
\begin{aligned}
& \text { bC1-x } 135 \text { RIVAFESFGGALCVESVDKEMRVLVGRIVSWMTTYLTDHLDPWIQENGGW } 134
\end{aligned}
$$

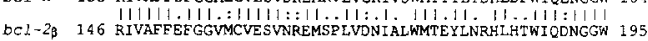

$$
\begin{aligned}
& \text { bel-K } 185 \text { VRTALP.... } 190 \\
& \text { bel-2ß } 196 \text { VGÄSGDUSLG } 205
\end{aligned}
$$

Figure 1. Nucleotide Sequence and Predicted Open Reading Frame of Chicken bcl-x

(A) The nucleotide sequence of chicken bcl-x represents a composite sequence derived from a cDNA clone and the corresponding genomic clone. The cDNA consisted of a $1.3 \mathrm{~kb}$ clone whose $5^{\prime}$ end is indicated by the arrow. The $5^{\prime}$ end of the sequence has been obtained from a genomic clone and shows the $5^{\prime}$ end of a predicted open reading frame as well as 257 additional nucleotides ending with a $5^{\prime}$ Narl site. The putative initiation codon conforms poorly to the consensus eukaryotic translation initiation sequence, while a consensus eukaryotic initiation sequence appears out-of-frame 32 nt $5^{\prime}$ of this site. Both the cDNA and genomic sequences end at a natural EcoRl site.

(B) The amino acid alignment of the predicted open reading frame from chicken $b c l-x$ (upper sequence) to the open reading frame from the human $b c l-2_{\beta}$ cDNA sequence (lower sequence). A search of GenBank revealed that bct-x displayed significant homology to all forms of $b c /-2$ present in GenBank, with highest homology to the $b c /-2_{\beta}$ form. It appears that, like the $b c /-2_{\beta}$ CDNA, the $b c /-x$ cDNA arose from an unspliced RNA, since it is colinear with the genomic sequence from which it is derived. 


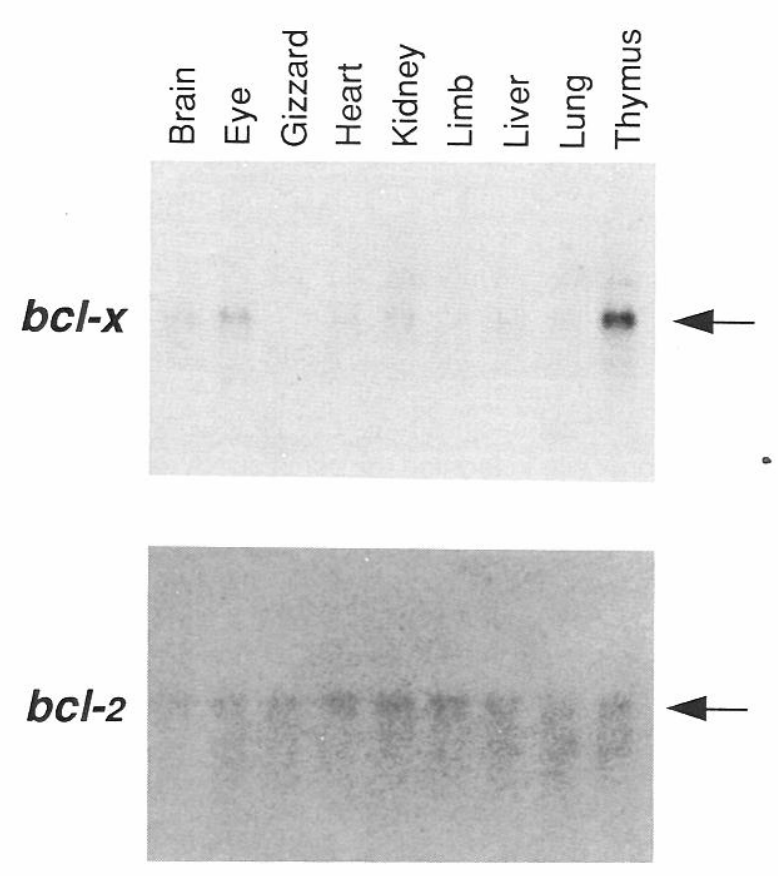

Figure 2. $b c l-x$ mRNA Expression in Tissues Isolated from a Newly Hatched Chicken

Tissue mRNAs isolated from a chicken on the day of hatching were hybridized with a chicken $b c l-x$-specific probe as well as a murine bcl-2 probe. At hatching, high levels of bcl-x mRNA were also observed in the bursa and spleen (data not shown). While the murine bcl-2 probe recognized a $6.5 \mathrm{~kb}$ mRNA, indicated by the arrow, that was present in all tissues tested, the $b c l-x$ probe hybridized to a $2.7 \mathrm{~kb}$ mANA, indicated by the arrow.

oping in these organs share a common feature in that cells from both locations undergo the rapid induction of programed cell death upon removal from the stromal components of the organ (Cooper et al., 1991; Neiman et al., 1991). Previous work in mammals has suggested that the bcl-2 proto-oncogene may play a role in the regulation of this event (McDonnell et al., 1989; Sentman et al., 1991; Strasser et al., 1991a). Therefore, we used a murine bcl-2 cDNA probe in an attempt to clone the avian bcl-2 homolog by low stringency hybridization. In the course of this project we isolated one clone, $b c l-x$, that displayed a pattern of hybridization that was distinct from the pattern we had obtained using the murine $b c /-2$ probe on Southern blots of chicken genomic DNA. The nucleotide sequence of $b c l-x$ displayed low level sequence identity $(56 \%)$ with bcl-2 and contained an open reading frame that showed significant similarity to the open reading frame found in the unspliced $b c /-2_{\beta}$ transcript derived from the $b c /-2$ gene in both humans and mice (Figures $1 A$ and $1 B$ ). Sequencing of $a$ genomic fragment containing $b c /-x$ demonstrated that our $1.3 \mathrm{~kb}$ cDNA had also arisen from a linear genomic sequence in the absence of splicing. This feature of the sequences raised the possibility that the bcl-x cDNA may have arisen from an unprocessed pseudogene present within the avian genome. Therefore, additional studies were performed to determine whether $b c /-x$ represented a functional bcl-2-related gene.

\section{bcl-x Is Expressed in Many Tissues and Is Highly Conserved in Vertebrate Evolution}

To characterize bcl-x further, its expression pattern was examined. Northern blot analysis of various tissue RNA samples isolated from a newly hatched chicken revealed that a bcl-x-specific probe hybridized to a $2.7 \mathrm{~kb}$ mRNA species present at highest levels in the thymus, bursa, and central nervous system (Figure 2). In contrast, a murine bc/-2-specific probe recognized an mRNA species of approximately $6.5 \mathrm{~kb}$ present at roughly equal levels in al tissues assayed.

We also examined the evolutionary conservation of $b c /-x$ by probing Southern blots containing chicken, mouse, and human DNA with $b c /-2$ and $b c l-x$ probes. Using chicken $b c l-x$ and mouse $b c l-2$ probes isolated from the region of highest sequence identity between chicken $b c l-x$ and the first coding exon of murine $b c /-2$, we found that both probes hybridized efficiently to DNA from all three species. However, the $b c /-x$ and $b c l-2$ probes bound to distinct segments of genomic DNA, suggesting that they were recognizing independent sequences, both of which have been highly conserved during vertebrate evolution (data not shown).

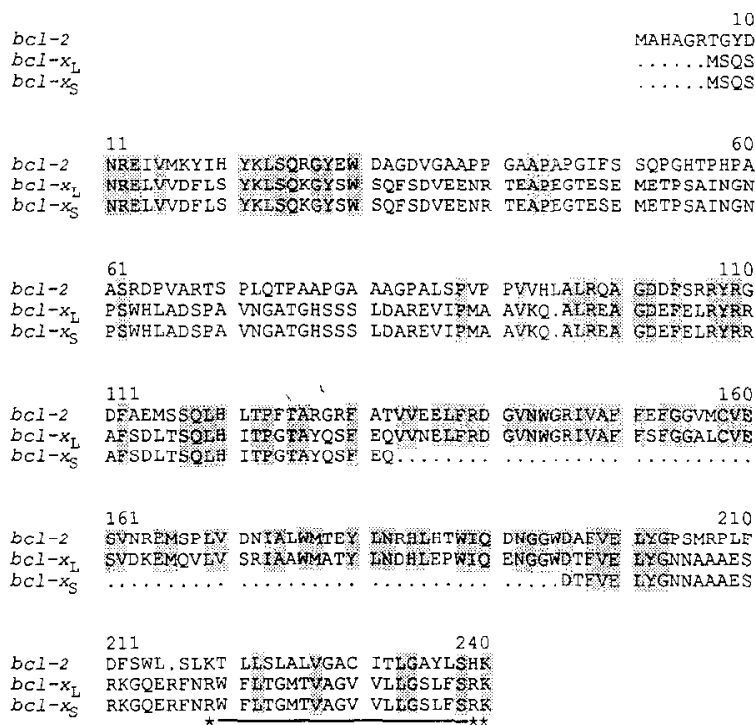

Figure 3. Predicted Amino Acid Sequence of Human mRNAs Related to Chicken bcl-x

The predicted open reading frames from the two distinct human cDNAs (bcl- $x_{1}$ and $b c l-x_{s}$ ) with homology to chicken bcl-x are displayed in comparison with human $b c l-2_{\alpha}(b c l-2)$. Areas of amino acid identity between human $\mathrm{BCl}-2$ and human $\mathrm{Bcl}-\mathrm{x}$ are indicated by stippling. The 63 amino acid region of human $B c l-x_{L}$ deleted in human $B c l-x_{3}$ is denoted by dots. A predicted 19 amino acid hydrophobic domain and flanking charged residues that are present in both $\mathrm{Bcl}-2$ and $\mathrm{Bcl} \cdot-\mathrm{X}$ are indicated by underlining and asterisks, respectively. The average hydrophobicity of this domain, which is present in both $\mathrm{Bcl}-\mathrm{x}_{\mathrm{L}}$ and Bcl- $x_{s}$, is 1.3 as calculated by the method of Kyte and Doolittle. This domain in Bcl-2 has previously been shown by Chen-Levy and Cleary (1990) to be required for the membrane localization. 


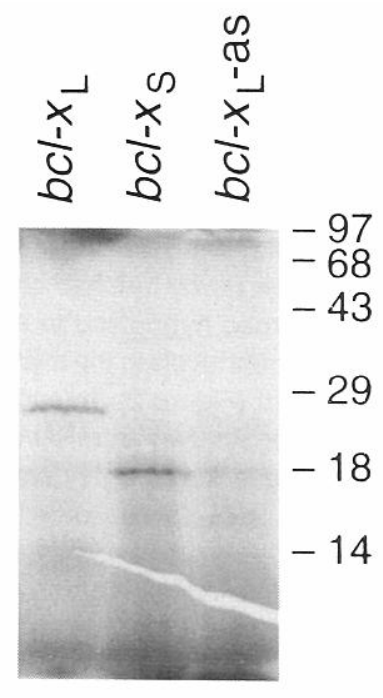

Figure 4. Translational Products of $b c l-x_{L}$ and $b c-1-x_{S} m R N A s$

Both $b c l-x_{\mathrm{L}}$ and $b c l-x_{\mathrm{S}} \mathrm{mRNAs}$ were subjected to in vitro translation in the presence of ${ }^{35} \mathrm{~S}$-radiolabeled methionine. The resulting translated proteins were run on an SDS-polyacrylamide gel. Sizes of the resulting proteins are indicated on the right in $\mathrm{kd}$. The result of a translation reaction using bcl- $\mathrm{x}_{\mathrm{L}}$ antisense mRNA (bcl- $\left.\mathrm{x}_{\mathrm{L}}-\mathrm{as}\right)$ is shown as a control to demonstrate the specificity of the translational products.

Identification of Two Distinct Human bc/-x cDNAs To study the potential significance of $b c /-x$ further, we next attempted to clone human homologs of $b c /-x$. By screening multiple cDNA libraries, we identified two separate types of human bcl-xcDNAs that contained distinct open reading frames flanked by identical $5^{\prime}$ and $3^{\prime}$ untranslated sequences. The larger type of cDNA, bcl- $x_{\mathrm{L}}$, contained an open reading frame with greater than $76 \%$ nucleotide and $74 \%$ amino acid identity ( $85 \%$ amino acid similarity) to chicken $b c /-x$. However, the human $b c /-x_{\llcorner}$cDNA diverged from the chicken $b c l-x$ sequence at a position corresponding to where the two coding exons of $b c /-2$ are joined to form the $b c /-2_{\alpha}$ transcript and where $b c /-2_{\alpha}$ diverges from $b c l-2_{\beta}$. Thus, human $b c /-x_{\mathrm{L}}$ displays greater similarity to $b c l-2_{\alpha}$ than $b c l-2_{\beta}$. It is the $b c l-2_{\alpha}$ transcript that encodes the functional activities previously ascribed to the bcl-2 gene. From the point of its divergence from the chicken $b c l-x$ sequence, the human $b c l-x_{\mathrm{L}}$ open reading frame extends another 45 amino acids before a termination codon is reached. The first 7 out of 8 of these novel amino acids were identical to amino acids encoded by the second coding exon of $b c /-2$ and present in the $b c /-2_{a}$, but not the $b c l-2_{\beta}$, mRNAs of both human and mouse (Figure 3; Tsujimoto and Croce, 1986; Negrini et al., 1987). The last 36 amino acids encoded by $b c /-x_{L}$ also showed significant sequence similarity to the hydrophobic domain of $\mathrm{Bcl}-2_{\alpha}$ thought to play a role in the insertion of the Bcl-2 protein into cytoplasmic membranes (Chen-Levy et al., 1989; Chen-Levy and Cleary, 1990). Consistent with the addition of these novel $b c l-x_{\mathrm{L}}$ sequences as a result of mRNA processing, the genomic sequence that encodes the last 45 amino acids of $b c /-x_{\mathrm{L}}$ is found on a separate exon from the exon that encodes the rest of the open reading frame (H. Yang and C. B. T., unpublished data).
The second type of human $b c /-x$-derived cDNA we identified, $b c /-x_{S}$, differs from $b c /-x_{\mathrm{L}}$ because it lacks the sequence that encodes a stretch of 63 amino acids present within the $b c /-x_{L}$ open reading frame (this region is indicated by a dotted line in Figure 3 ). This deletion occurs as a result of the splicing of the second coding exon observed in bcl- $x_{\mathrm{L}}$ to a more proximal 5' splice donor within the first coding exon. The addition of the $\mathbf{4 5}$ amino acids derived from the second coding exon begins precisely at the position of a potential splice donor site, AG/GT, located within the open reading frame of $b c /-x_{L}$. The use of this splice donor site in forming the $b c l-x_{5}$ cDNA results in the deletion of the 63 amino acid sequence that displays greatest similarity between $b c /-2$ and $b c /-x$. This amino acid sequence displays $73 \%$ identity with the same region in human $\mathrm{Bcl}-2$. This region of $b c \mathrm{l}-2$ is also the most highly conserved region among chicken, murine, and human bcl-2 (Cazals-Hatem et al., 1992; Eguchi et al., 1992).

To demonstrate that the $b c l-x_{\mathrm{L}}$ and $b c l-x_{S}$ open reading frames could lead to an appropriately sized protein product, both cDNA species were transcribed as RNA and then subjected to in vitro translation. As seen in Figure 4, both $b c /-x_{L}$ and $b c l-x_{S} C D N A s$ resulted in translational products of the approximate size predicted by the open reading frames.

\section{$b c / \cdot x_{\mathrm{L}}$ Can Serve as an Inhibitor of Apoptotic Cell Death}

Because of the close similarities between the $b c /-x_{\mathrm{L}}$ and the functional form of $b c l-2, b c l-2_{a}$, we sought to determine whether $b c l-x_{L}$ could serve a similar function in preventing apoptotic cell death. To this end, the murine IL-3-dependent prolymphocytic cell line FL5.12 was transfected with the human $b c /-x_{1}$ cDNA inserted into the EcoRl cloning site of the PSFFV-Neo expression plasmid. Cells were selected for neomycin resistance for 10 days and then used as a polyclonal population to test their resistance to apoptosis following removal of IL-3. bc/- $x_{\mathrm{L}}$-transfected cells had similar growth kinetics to the parental cell line as well as to neomycin-transfected control cells. For comparison, cells were also transfected with the human $b c /-2_{\alpha}$ open reading frame inserted in the EcoRI cloning site of pSFFV-Neo. Neomycin-resistant cells were then subjected to IL-3 deprivation, and the number of surviving cells was calculated in triplicate beginning at the time of IL-3 deprivation. As can be seen in Figure 5, FL5.12 cells transfected with the neomycin construct alone underwent rapid cell death following the removal of the growth factor. Serial examination revealed that these cells underwent apoptosis, as manifested by plasma membrane blebbing, cell volume loss, nuclear condensation, and degradation of nuclear DNA at nucleosomal intervals, as previously reported (Hockenbery et al., 1990; Nuñez et al., 1990). In contrast, $b c l-2$-transfected cells demonstrated significant resistance to cell death and could be readily induced to reenter the cell cycle upon readdition of IL-3. Expression of $\mathrm{Bcl}-2$ in greater than $95 \%$ of the bulk transfected cells was demonstrated by specific staining with a Bcl-2-specific monoclonal antibody.

When stable $b c l-x_{\mathrm{L}}$ transfectants were subjected to IL-3 


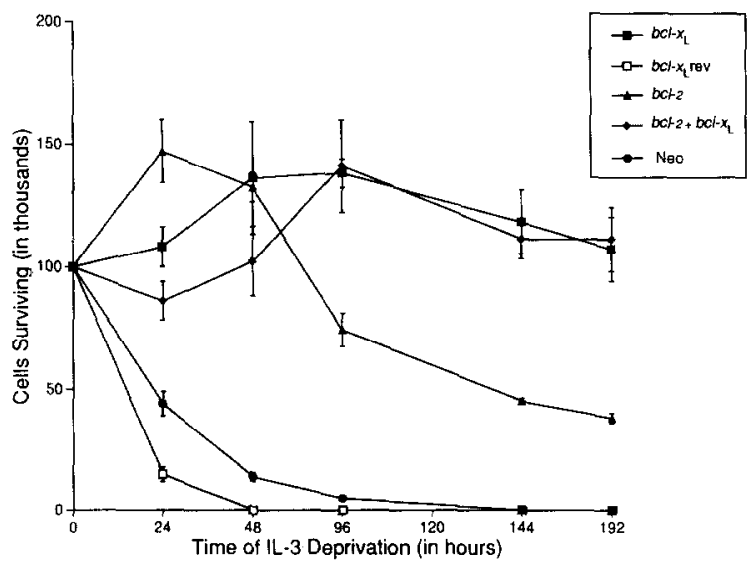

Figure 5. The Effect of $b c /-x_{L}$ Expression on FL5.12 Cell Survival following IL-3 Withdrawal

Stable transfectants of FL5.12 with the pSFFV-Neo vector containing bcl- $x_{\mathrm{L}}$ in the forward (bcl- $\mathrm{x}_{\mathrm{L}}$; closed square) and reverse (bcl- $\mathrm{x}_{\mathrm{L}}$ rev; open square) orientations, $b c /-2$ (closed triangle), $b c /-2+b c /-x_{L}$ (closed diamond), and vector control (Neo; closed circle) were prepared as described in Experimental Procedures. Cell survival was determined by trypan blue exclusion at the indicated time points. Data are presented as the mean \pm SD of triplicate cultures.

deprivation, they displayed dramatic resistance to cell death with essentially no loss of cell viability over the 8 day culture period. This resistance to cell death was significantly greater than the resistance of bcl-2-transfected cells in which there was a reproducible $50 \%$ decrease in surviving cell number over a similar time period (Figure 5). Cotransfection of $b c l-2$ and $b c l-x_{L}$ did not improve cell survival beyond that of transfection with $b c /-x_{L}$ alone. The dramatic survival of $b c /-x_{L}-$ transfected cells was not due to ongoing cell proliferation as a result of transformation or the induction of growth factor-independent cell proliferation. Following IL-3 deprivation, the cells rapidly took on a quiescent phenotype, arresting in a G0/G1 phase of the cell cycle as measured by cell size and DNA content, and did not reenter cell cycle until IL-3 was readded. Readdition of IL-3 led to rapid blast transformation and cell cycle progression (data not shown). These data suggest that expression of $b c l-x_{\mathrm{L}}$ can lead to significant resistance to apoptotic cell death that is at least as great as that conferred by $b c /-2$. This property of bcl- $x_{1}$-transfected cells does not appear to result from cellular transformation that results in IL-3-independent cell growth.

\section{bcl-xs Can Inhibit the Ability of bc/-2 to Prevent Apoptotic Cell Death}

To determine whether the $b c /-x_{s}$ isoform of $b c l-x$ plays a role in the regulation of apoptotic cell death, FL5.12 cells were stably transfected with a human $b c /-x_{S}$ expression plasmid (Figure 6). Stable transfectants were easily isolated, and their expression of bcl-xs mRNA was confirmed by Northern blot analysis (Figure $6 \mathrm{C}$ ). In the presence of IL-3, these cells appeared morphologically normal and displayed growth characteristics indistinguishable from the parental cells or neomycin-transfected controls. Furthermore, the cells died with kinetics indistinguishable from neomycin-transfected control cells upon deprivation of IL-3. bcl-2-transfected cells again displayed characteristic resistance to apoptotic cell death upon removal of IL-3. Remarkably, however, when bcl- $x_{S}$ was cotransfected with bcl-2 and stable transfectants were isolated, the cells reacquired sensitivity to growth factor withdrawal, undergoing apoptotic cell death upon IL-3 deprivation. Nevertheless, there was a significant delay in the onset of cell death within this polyclonal population. The sensitivity to IL-3 deprivation of cells cotransfected with $b c /-2$ and $b c l-x_{S}$ was not the result of reduced $\mathrm{Bcl}-2$ expression, since bulk populations of both $b c l-2$ - and $b c l-2+b c l-x_{S}-$ transfected cells displayed roughly equivalent levels of $\mathrm{Bcl}-2$ protein. To determine the magnitude of the ability of $b c /-x_{S}$ to inhibit $b c 1-2$ function, a number of subclones were isolated from the cotransfected population of cells. All of these cells expressed high levels of transfected bcl-2, and all demonstrated a reduced resistance to apoptotic cell death upon growth factor withdrawal, with some clones demonstrating an almost complete abrogation of bcl-2 function in the presence of $b c /-x_{S}$ expression (Figure 6B). Furthermore, when assayed at 24 and $48 \mathrm{hr}$ after IL-3 deprivation, DNA from cells cotransfected with $b c l-2$ and $b c l-x_{S}$ showed a clear nucleosomal pattern of degradation, while DNA from cells transfected with $b c /-2$ alone or bcl- $x_{L}$ alone did not (data not shown). Although there was a rough correlation between the inhibition of bcl-2 function and the bcl- $x_{s}$ mRNA levels expressed by the cells, the precise stoichiometry between bcl- $x_{S}$ expression and $b c l-2$ functional inhibition could not be determined further because of our inability to quantitate $b c /-x_{s}$ protein levels at the present time. Nevertheless, in three independent bulk transfections and in all subclones that coexpress both bcl-2 and $b c l-x_{s}$, we observed significant inhibition of bcl-2-induced resistance to apoptosis by coexpression of $b c l-x_{s}$. The average survival of bcl-2-transfected cells $96 \mathrm{hr}$ after IL-3 removal was $79 \% \pm 14 \%$ (mean $\pm S D, n=3$ ), while the average survival of subclones coexpressing bcl-2 and $b c l-x_{S}$ was $8 \% \pm 8 \%($ mean $\pm S D, n=6)$.

This induction of apoptotic cell death required that the $b c t-x_{s}$ construct be expressed in the sense orientation, as stable introduction of a pSFFV-Neo plasmid containing $b c l-x_{3}$ cloned in the antisense orientation had no effect on the ability of bcl-2 to prevent apoptotic cell death upon growth factor deprivation (data not shown). Together, these data suggest that the expression of the $b c l-x_{s}$ isoform of the $b c /-x$ gene may play an important and apparently dominant role in regulating the ability of other growth survival genes such as bcl-2 to prevent apoptotic cell death. Thus, high level expression of $b c l-x_{s}$ appears to make the FL5.12 cells absolutely dependent upon growth factor, rendering them resistant to the ability of bcl-2 to prevent apoptosis upon growth factor withdrawal.

\section{Expression of $b c l-x$ during $T$ Cell Development and Activation}

The highest level of mRNA for bcl-x in chickens was observed in the organs where lymphoid development takes place. To characterize further the expression of bcl-x in human lymphocytes, we analyzed its expression in human 

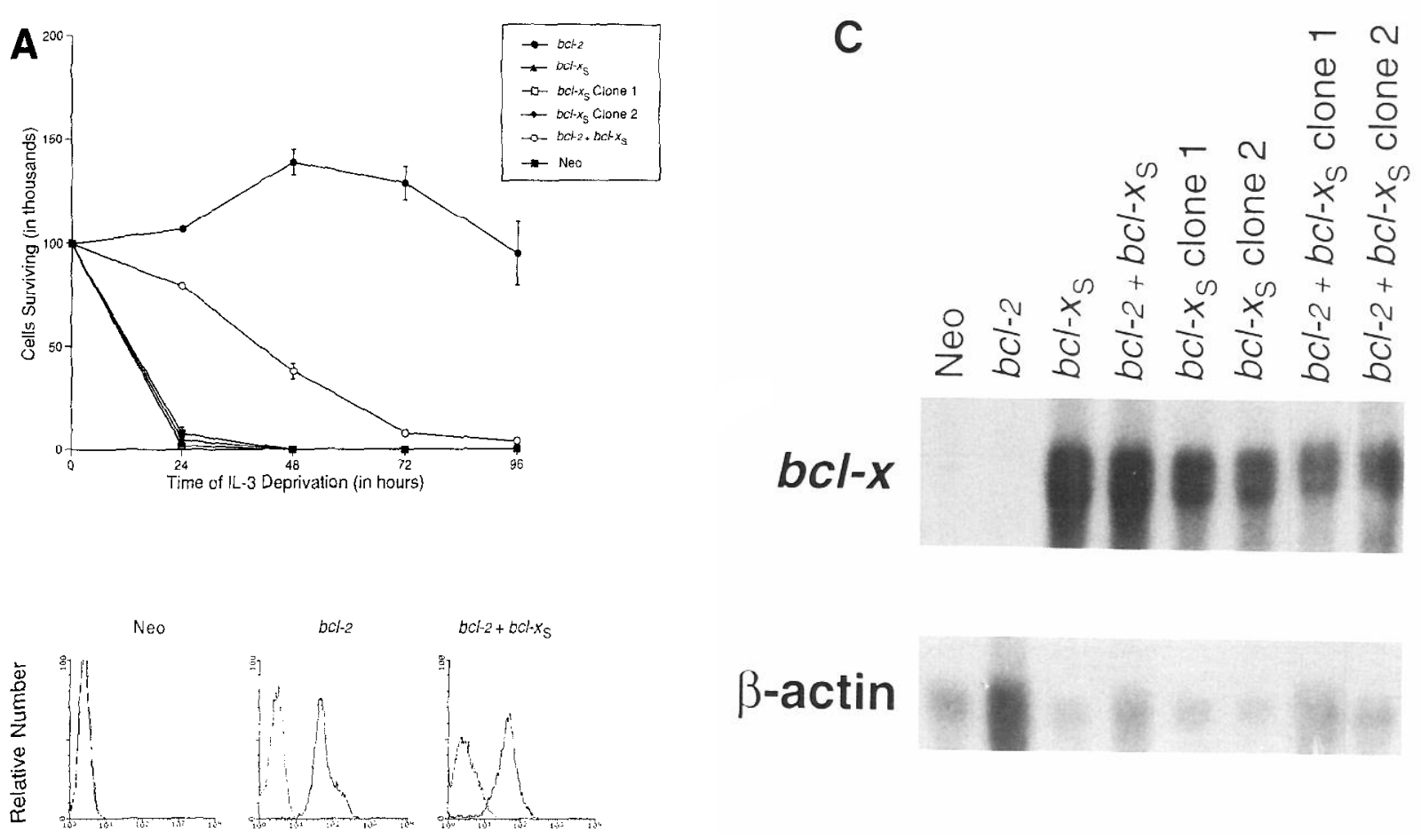

Fluorescence

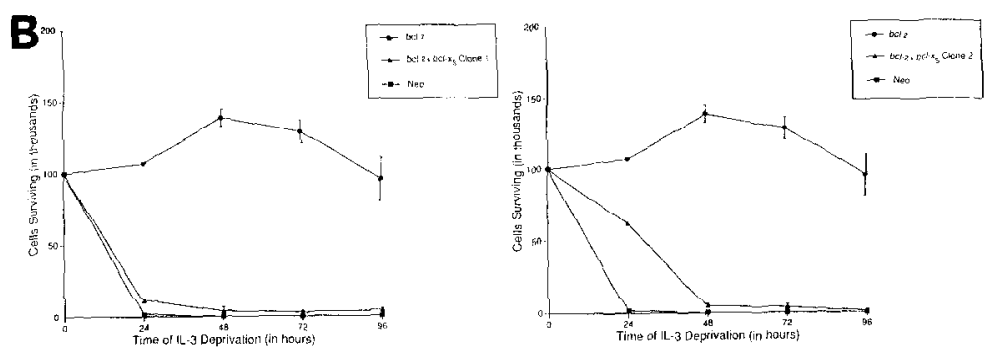
Figure 6. Stable Expression of $b c l-x_{s}$ Prevents bct-2-Induced Survival of FL5.12 Cells upon IL-3 Withdrawal

(A) Stable transfectants of FL5.12 expressing bcl-2 (closed circle), bcl- $x_{\mathbf{S}}$ (closed triangle), $b c l-2+b c /-x_{s}$ (open circle), or the selectable marker neomycin (NeO; closed square) alone were prepared as described in Experimental Procedures. In addition, individual subclones of $b c l-x_{s}$ (bcl-x $x_{s}$ Clone 1 [open square] and bcl$x_{S}$ Clone 2 [closed diamond]) were analyzed. At time 0, exponentially growing cells were withdrawn from IL-3 support, and survival was analyzed over time by trypan blue exclusion. The lower portion of the figure shows the flow cytometry analysis of the neomycin (NeO), $b c l-2$, and $b c l-2+b c /-x_{s}$ bulk populations. Cells were permeabilized as indicated in Experimental Procedures and then stained with a monoclonal antibody specific for human bcl-2 (thick line) or an irrelevant control antibody (thin line). (B) Survival of individual $b c t-2+b c /-x_{s}$ subclones following IL-3 withdrawal. The survival

\section{Fluorescence}

of subclones expressing both $b c /-2$ and $b c l-x_{s}$ was analyzed following growth factor withdrawal as described above (bcl-2 $+b c /-x_{s}$ Clone 1 and $b c t-2+b c l-x_{s}$ Clone 2). The lower half of the figure shows flow cytometry analysis for bct-2 expression in the neomycin, bcl-2, bct-2 + bcl- $x_{S}$ Clone 1 , and $b c t-2+b c t-x_{s}$ Clone 2 populations. Cells were permeabilized as described in Experimental Procedures and then stained with a monoclonal antibody specific for human bcl-2 (thick line) or an irrelevant control isotype-matched antibody (thin line); the data are displayed as fluorescence intensity versus cell number.

(C) Expression of bchx RNA in stably transfected FL5.12 cell lines. RNA was isolated from each of the clones indicated above and analyzed on a Northern blot by hybridization with bol-x-specific and $\beta$-actin-specific probes.

thymocytes and peripheral blood T cells. As seen in Figure $7, b c /-x$ mRNA can be readily detected in human thymocytes. However, upon fractionation of human thymocytes into immature and mature populations, we found that, in the absence of mitogen stimulation, bc/-x expression is confined to the immature double-positive thymocytes, which express both CD4 and CD8. bct-x mRNA was not detected in unstimulated mature single-positive (CD4 ${ }^{+}$. $\mathrm{CD8}^{-}$and $\mathrm{CD}^{-} \mathrm{CD8}^{+}$) thymocytes or in peripheral blood $T$ cells. A significant difference in these populations was 


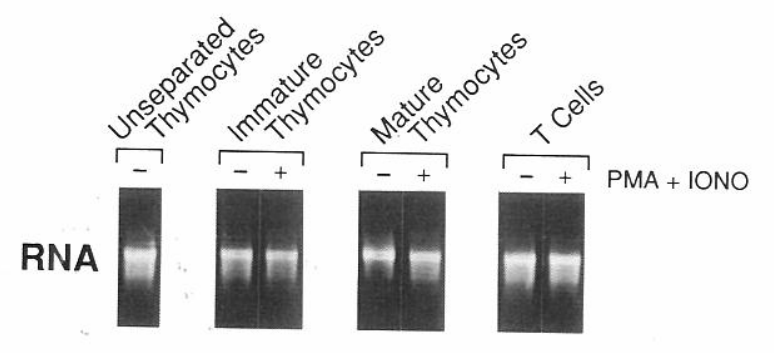

$b c /-x$
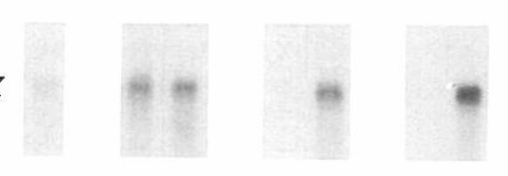

HLA
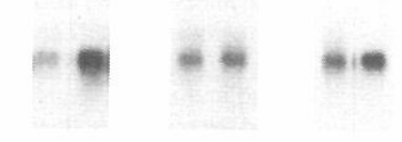

Figure 7. Expression of bcl-x in Human Thymocytes and $T$ Cells To examine the expression of $b c l-x$ during $T$ cell development, RNA was prepared from unseparated thymocytes, immature thymocytes, mature thymocytes, and peripheral blood T cells as described in Experimental Procedures. The immature thymocytes, mature thymocytes, and T cell populations were further analyzed by stimulation in vitro with PMA and ionomycin for 6 to $8 \mathrm{hr}$ in complete media. Resulting RNAs were isolated by the guanidinium isothiocyanate method and subjected to Northern blot analysis. The top panels demonstrate the equalization of the RNA samples used for analysis, and the lower two panels represent hybridization with a bct-x-specific probe or a human leukocyte antigen (HLA) class I-specific probe.

also uncovered when these isolated cell populations were stimulated with the mitogenic combination of phorbol myristate acetate (PMA) and ionomycin. Six hours of stimulation with PMA and ionomycin had no effect on bcl-x mRNA expression in double-positive thymocyte populations but induced a dramatic increase in bcl-x mRNA expression in both single-positive thymocytes and peripheral blood $T$ cells. Thus, it appears that bcl-x mRNA is expressed constitutively in T cells with immature phenotypes that are in the process of undergoing developmental selection. Cells that have completed developmental selection downregulate the expression of $b c /-x$, but $b c l-x$ expression can be rapidly induced by $T$ cell activation.

bcl-2 has also been reported to be induced upon $T$ cell activation (Graninger et al., 1987; Reed et al., 1987), and we sought to compare the kinetics of bcl-x induction with that of bcl-2 induction in peripheral blood T cells. Peripheral blood $T$ cells were isolated at various time points after activation with a mitogenic combination of PMA and ionomycin (Figure 8). bcl- $x$ was rapidly induced upon activation with detectable mRNA, appearing within the first $6 \mathrm{hr}$ after stimulation. Thereafter, $b c l-x$ mRNA was expressed at a relatively constant level. In contrast, $b c l-2$ mRNA was first detected between 6 and $12 \mathrm{hr}$ after activation and underwent progressive accumulation over the first $24 \mathrm{hr}$ in culture following mitogen activation. Similar results were obtained following antigen-receptor cross-linking (data not
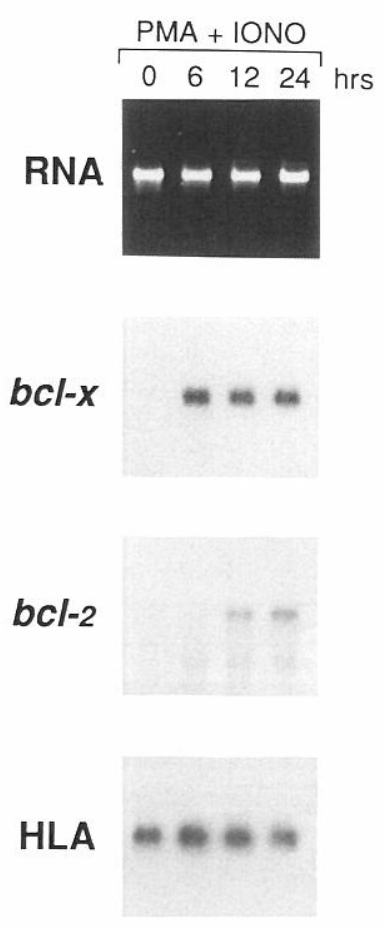

Figure 8. Pattern of $b c /-x$ and $b c /-2$ mRNA Induction Following Peripheral Blood T Cell Activation

Peripheral blood T cells were isolated as described in Experimental Procedures and then subjected to activation with a combination of PMA and ionomycin for $0,6,12$, or $24 \mathrm{hr}$, as indicated. The relative induction of $b c /-x$ and $b c /-2$ was analyzed by equalizing RNA from the different time points for ribosomal RNA (upper panel). Duplicate Northern blots were probed for either $b c l-x$ or $b c /-2$ and human leukocyte antigen (HLA) class I mRNA. In the data shown, the bcl-x autoradiogram has been exposed for $8 \mathrm{hr}$, while the bcl-2 autoradiogram has been exposed for 15 days; both probes were of similar length and base composition.

shown). Since the two probes used to detect $b c /-x$ and bcl-2 are of similar size and GC content, we were able to estimate the differences in the steady-state mRNA levels between $b c l-x$ and $b c /-2$. There appears to be an approximately 50-fold difference in the steady-state accumulation of $b c l-x$ and $b c l-2$ mRNA, even after $24 \mathrm{hr}$ of cell activation. Thus, bcl-x mRNA accumulation occurs more rapidly and to a higher steady-state level than does the induction of $b c l-2$ mRNA upon T cell activation. How closely these differences in mRNA expression correlate with differences in the protein level cannot be determined at present. Such analyses will also be important since bcl-2 mRNA and protein levels do not always correlate well in human lymphoid tissues (Chleq-Deschamps et al., 1993).

Tissue-Specific Expression of $b c /-x_{L}$ and $b c / \cdot x_{S}$ The difference in size between the $b c /-x_{\mathrm{L}}$ and $b c /-x_{S}$ cDNA is too small to distinguish by Northern blot analysis. To determine which forms of the mRNA are being expressed during $T$ cell development and activation, we utilized the polymerase chain reaction ( $P C R$ ) to quantitate the relative abundance of the two mRNAs in a series of RNA samples (Figure 9). PCR primers that bind to sequences shared 

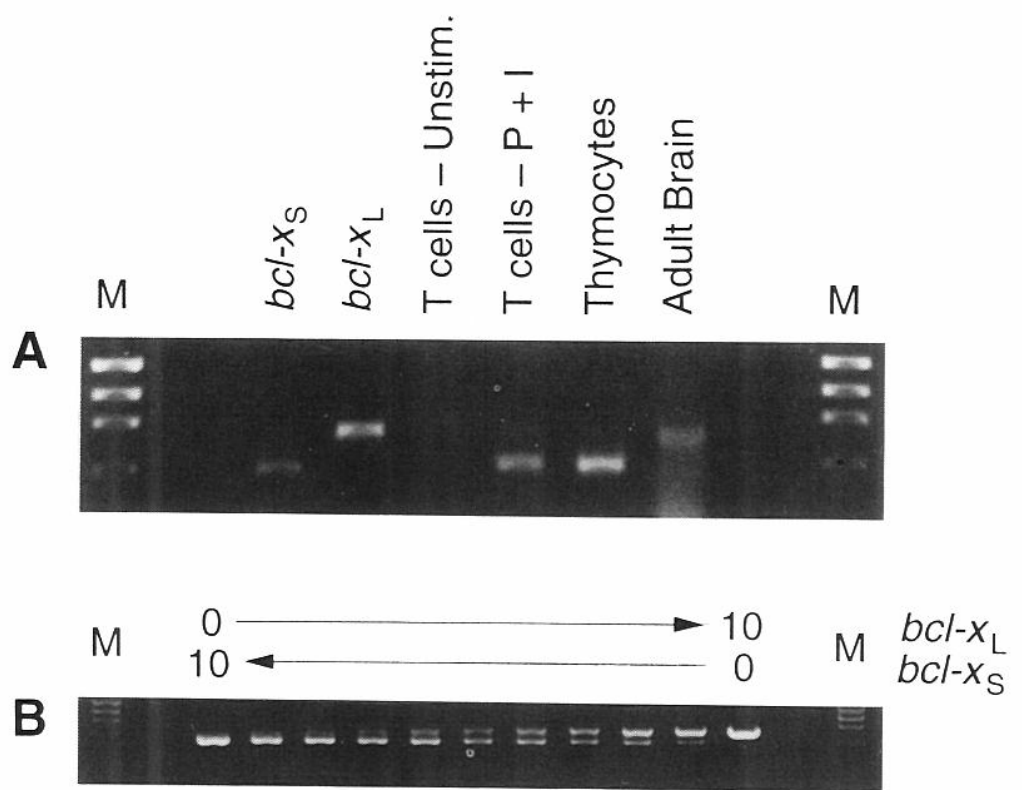

Figure 9. Analysis of Relative Proportions of $b c l-x_{s}$ and $b c /-x_{L}$ mRNAs Expressed in Human Thymocytes, $T$ Cells, and Adult Brain

PCR primers that flank the $5^{\prime}$ and $3^{\prime}$ ends of the open reading frame of $b c l-x_{\mathrm{s}}$, as described in Experimental Procedures, were used to amplify $b c l-x_{L}$ and $b c l-x_{S}$ simultaneously. Using these primers, RNAs from various sources were subjected to PCR analysis. When a $b c l-x_{5}$ template was utilized, a single band of 591 bp was produced, whereas when a $b c l-x_{\mathrm{L}}$ template was used, a single band of $780 \mathrm{bp}$ was observed. Molecular weight markers from Haelldigested $\phi \times 174$ are indicated (M).

(A) Lanes represent products from PCRs using a $b c l-x_{S}$ template and a $b c l-x_{L}$ template, and using RNA from unstimulated peripheral blood $T$ cells, peripheral blood $T$ cells stimulated for $6 \mathrm{hr}$ with PMA and ionomycin, unseparated human thymocytes, and adult brain. The identification of the observed bands in the tissue samples as $b c /-x_{L}$ and $b c t-x_{S}$ has been verified by cloning and partial sequencing of PCR products of reverse transcribed RNA from each of the tissue sources.

(B) A titration curve to demonstrate the validity of the PCR assay in quantitating the relative ratios of $b c l-x_{\mathrm{L}}$ and $b c h-x_{\mathrm{S}}$. The figure depicts the products of PCRs separated on $1 \%$ agarose gels and stained with ethidium bromide. The PCR was performed using a ratio of $b c t-x_{L}: b c l-x_{S}$ that varied from 0:10 to 10:0 in unit increments. The resulting products reflect the relative proportions of $b c t-x_{L}$ and $b c l-x_{S}$ template added to the reaction mix.

by $b c l-x_{L}$ and $b c /-x_{S}$ and that flank the region that is deleted in $b c /-x_{S}$ were used as primers to amplify mRNA following reverse transcription. These two primers are located on separate coding exons, and therefore the product of any contaminating genomic DNA will be considerably larger than the products of the RNA species of interest. Under the conditions of the PCR reactions, the relative ratios of the two bcl-x mRNA species can be measured as demonstrated in the control experiment presented in Figure 9B. Using this PCR assay, we studied the bcl-x mRNA species present in unfractionated thymocytes and in peripheral blood T cells cultured in media alone or stimulated for $6 \mathrm{hr}$ with PMA and ionomycin. As suggested by the Northern blot analyses, resting $T$ cells do not express $b c l-x$ transcripts that can be identified by PCR. In contrast, activated $T$ cells express an easily detectable PCR product made up predominantly of the $b c /-x_{s}$ form. Unfractionated thymocytes also express bcl-xs mRNA almost exclusively. These data suggest that both activated $T$ cells and doublepositive thymocytes selectively express the form of $b c /-x$ that enhances the dependence of the cell on exogenous signals to prevent apoptosis. This finding is consistent with the inability of overexpression of bcl-2 to overcome negative selection during the development of double-positive thymocytes as well as the failure of bcl-2 overexpression to increase $T$ cell numbers significantly during peripheral $T$ cell responses.

The other major tissue in chickens that demonstrated a relatively high level of $b c /-x$ expression by Northern blot analysis was the central nervous system. PCR analysis of adult human brain mRNA shows expression exclusively of the bcl- $x_{\mathrm{L}}$ mRNA species (Figure 9A). Therefore, it appears that different tissues can differentially regulate both the expression and splicing of bcl- $x$ and thus adapt the functional properties of this gene to regulate their relative sensitivity to potential mediators of apoptotic cell death.

\section{Discussion}

In this report we have identified and characterized a bc/-2related gene, $b c /-x$. The $b c /-x$ gene has been highly conserved in vertebrate evolution, and bcl-x mRNA is expressed in a variety of tissues, with the highest levels of mRNA observed in the lymphoid and central nervous systems. We have isolated two distinct $b c l-x$ mRNA species from human tissues. These two cDNAs result from the alternative use of two distinct $5^{\prime}$ splice sites located within the first coding exon of the $b c l-x$ gene. The longer cDNA, $b c /-x_{L}$, encodes a protein that appears to be similar in size and predicted structure to Bcl-2. The shorter cDNA, $b c /-x_{S}$, contains a deletion of the 63 amino acids from the $b c /-x_{\mathrm{L}}$ open reading frame that constitutes the region of highest amino acid identity between $B C l-x_{L}$ and $B c l-2$. Stable transfection of $b c /-x_{L}$ prevented apoptotic cell death following growth factor deprivation of an IL-3-dependent cell line to an even greater extent than did overexpression of bcl-2. The combination of the two vectors was no better at preventing apoptotic cell death than $b c /-x_{L}$ alone. This suggests that $b c /-x_{L}$ plays a major role in regulating the dependence of cells on continuous exogenous signals to prevent cell death. In contrast, the stable expression of $b c /-x_{S}$ had no effect on cell growth in the presence of growth factor or on the rate of apoptotic cell death following growth factor removal. However, $b c /-x_{s}$ could prevent the ability of stable bcl-2 expression to inhibit apoptotic cell death upon growth factor removal. Together, these data suggest that the expression of $b c /-x_{S}$ can play a dominant role to $b c /-2$ in the regulation of apoptotic cell death. Under our assay condi- 
tions, $b c l-x_{S}$ expression increased the dependence of the cells on exogenous signals such as growth factors to prevent cell death actively.

Based on these observations, we went on to examine $b c l-x$ mRNA expression during human $T$ cell development and activation. Within the thymus, bcl- $x$ was expressed in immature double-positive thymocytes but was not observed in freshly isolated single-positive thymocytes or peripheral blood T cells. The bcl-x mRNA species found in the double-positive thymocytes was almost exclusively of the $b c l-x_{S}$ form. Previous studies have shown that $b c /-2$ does not inhibit negative selection that normally occurs at the double-positive stage of thymocyte development (Sentman et al., 1991; Strasser et al., 1991a). The stable expression of $\mathrm{bcl}-\mathrm{x}_{\mathrm{S}}$ at this stage of development provides a potential explanation for this observation. Nevertheless, it has been shown that $b c /-2$ can prevent some forms of apoptosis that occur in double-positive thymocytes (Sentman et al., 1991; Strasser et al., 1991a; Siegel et al., 1991). This suggests that the influence of $b c l-2$ relative to $b c l-x_{S}$ in regulating the central events involved in apoptotic cell death may vary depending on the pathway that initiates the cell death response. Alternatively, down-regulation of $b c l-x$ expression at the mRNA or protein level may permit the effects of $b c /-2$ to predominate. Under these conditions, it may be possible for overexpression of $b c /-2$ to prevent apoptotic cell death.

Although single-positive thymocytes and mature peripheral blood T cells fail to express bcl-x mRNA, both populations can be rapidly induced to express high levels of $b c l-x$ mRNA following mitogenic activation. Again, the predominant mRNA species observed encodes $b c l-x_{S}$. This suggests that $T$ cell activation induces the expression of $b c l-x_{S}$ to increase the dependence of the cell on the growth factors provided in its local environment. Several groups have shown that activation of peripheral T cells can render them susceptible to apoptosis (Kawabe and Ochi, 1991; Webb et al., 1990), a finding previously at odds with the upregulation of bcl-2 expression observed following $T$ cell activation (Graninger et al., 1987; Reed et al., 1987). The inducible expression of $b c /-x_{s}$ in these populations may serve to regulate the amplification of $T$ cells involved in an immune response by making them highly dependent on continuous exogenous signaling to prevent their deletion by apoptosis. Thus, it appears that the differential regulation of bcl-x during $T$ cell development and $T$ cell activation may play a central role in regulating two important forms of apoptosis occurring in this cell lineage that were previously reported to be regulated independently of $b c /-2$. Based on these preliminary studies, it appears that $b c l-x_{S}$ expression plays an important role in the regulation of both developmentally and activationally induced cell death. Further characterization of these issues will be possible upon development of $b c /$-x-specific antibodies as well as delineation of $\mathrm{bcl}-\mathrm{x}_{\mathrm{S}}$ regulation during cell development and activation within nonlymphoid tissues.

Based on our characterization of $\mathrm{BCl}-\mathrm{x}_{\mathrm{L}}$ as a gene product that could mediate significant resistance to growth factor-dependent cell death, we wondered whether expression of $b c /-x_{L}$ might be observed in long-lived postmitotic cells. To address this possibility, we analyzed the expression of bcl-x in adult neural tissue. We found that $b c l-x$ was constitutively expressed in adult brain exclusively as $b c l-x_{L}$ mRNA. Thus, expression of $b c l-x_{L}$ is correlated with the ability of adult neural tissue to maintain long-term postmitotic cell viability. It will be important in future studies to address the relative regulation of the two bcl-x mRNA forms during neural development and their potential roles in neuronal loss in various neural degenerative diseases. Cell loss in several of these disorders has been hypothesized to occur by apoptosis (Oppenheim, 1991). This could result from internal mechanisms that inhibit bcl- $x_{L}$ function, thus leading to increased neural cell susceptibility to cell death. Alternatively, altered regulation of $b c /-x$ expression or splicing may play a role in the pathogenesis of this important set of diseases.

$b c l-x$ was originally identified on the basis of its similarity to $b c /-2$. This similarity is greatest within a short domain at the amino terminus of the protein, a highly conserved domain located internally within the protein (previously termed bcl-2 domain 4; Eguchi et al., 1992), and a hydrophobic domain that appears to confer membrane loca!ization to the Bcl-2 protein (Chen-Levy and Cleary, 1990). Domain 4 has been deleted in bcl-xs. This is the most highly conserved domain within bcl-2 genes isolated from different species as well as the most conserved region between $b c l-x$ and $b c l-2$. Our studies identify this domain as playing a critical role in the ability of these proteins to prevent the activation of programed cell death.

One potential mechanism by which $\mathrm{Bcl}-\mathrm{x}_{\mathrm{S}}$ could act as a dominant inhibitor of $\mathrm{Bcl}-2$ function is by forming an inactive heteromeric complex with $\mathrm{Bcl}-2$. We have investigated this possibility by trying to demonstrate an in vitro association between $\mathrm{Bcl}-2$ and either $\mathrm{Bcl}-\mathrm{x}_{\mathrm{S}}$ or $\mathrm{Bcl}-\mathrm{x}_{\mathrm{L}}$. To date, using in vitro cotranslation of the proteins in the presence or absence of membranes, we have been unable to obtain any evidence that $\mathrm{Bcl}-2$ and either $\mathrm{Bcl}-\mathrm{x}_{\mathrm{S}}$ or $\mathrm{Bcl}-\mathrm{x}_{\mathrm{L}}$ can interact directly (L. H. B. and C. B. T., unpublished data). Nevertheless, Korsmeyer and colleagues have recently obtained evidence that one of the proteins that Bcl-2 associates with intracellularly displays amino acid similarity to $\mathrm{Bcl}-2$ (S. Korsmeyer, personal communication). It therefore remains possible that the mechanism by which Bcl-Xs regulates $\mathrm{Bcl}-2$ function results from a specific interaction between the two proteins. An alternative explanation for our data is that $\mathrm{Bcl}-\mathrm{x}_{\mathrm{S}}$ and $\mathrm{BCl}-\mathrm{x}_{\mathrm{L}}$ may bind directly to the same downstream regulators of apoptosis as Bcl-2. If this were the case, we would hypothesize that this proteinprotein interaction domain lies within the amino-terminal domain that shows a high degree of amino acid similarity between $\mathrm{Bcl}-2$ and both $\mathrm{Bcl}-\mathrm{x}_{\mathrm{S}}$ and $\mathrm{Bcl}-\mathrm{x}_{\mathrm{L}}$. The 63 amino acid domain deleted from Bcl- $x_{S}$ might then play a critical role in determining the effect of this protein-protein interaction on the regulation of the downstream events involved in apoptosis. In this model, Bcl-x could bind to and enhance the function of downstream mediators of apoptosis, while Bcl- $x_{L}$ would bind to and prevent the activation of such mediators. To account for the ability of $\mathrm{Bcl}-\mathrm{x}_{\mathbf{S}}$ to function in the presence of high level expression of $\mathrm{Bcl}-2$, the effect of $\mathrm{Bcl}-\mathrm{x}_{\mathrm{S}}$ would have to out-compete that of $\mathrm{Bcl}-2$, 
perhaps via a higher affinity interaction with the putative downstream regulators of apoptosis. There may also be as yet unidentified posttranslational modifications of $\mathrm{Bcl}-2$, $\mathrm{BCl}-\mathrm{x}_{\mathrm{S}}$, and/or Bcl- $\mathrm{x}_{\mathrm{L}}$ that may account for the ability of these proteins to affect differentially the outcome of distinct cellular pathways that can lead to apoptosis.

In conclusion, our findings suggest that $b c /-x$ may play an important role in the regulation of developmental and tissue-specific programed cell death. bcl-x function appears to be regulated at both the level of mRNA expression and the level of splicing. The expression of $b c l-x_{S}$ may account for several situations in which $b c /-2$ expression does not overcome developmentally or activationally regulated cell death, such as negative selection in the thymus or activation-induced cell death in T cells. The steady-state expression of $b c /-x_{L}$ may contribute to the resistance of adult neural cells to cell death upon the reduction in the growth factor activity that occurs following the completion of neural development. Together, our data suggest that $b c l-x$ plays a central role in the regulation of cell death and may account for several forms of apoptosis previously proposed to occur by intracellular mechanisms that either bypass or are regulated independently of $b c /-2$.

\section{Experimental Procedures}

\section{Cloning and Construction of Plasmids}

Chicken bursal, spleen, and thymic cDNA libraries and a genomic library that was made from red blood cells were screened with a murine bch-2 cDNA at low stringency. The filters were hybridized in Stark's solution (50\% formamide, $5 \times$ SSC [ $1 \times$ SSC is $0.15 \mathrm{M} \mathrm{NaCl}$ and 0.015 sodium citrate], $1 \times$ Denhardt's solution, $24 \mathrm{mM}$ sodium phosphate [pH 6.5], $250 \mu \mathrm{g} / \mathrm{ml}$ RNA) with $10 \%$ dextran sulfate at $42^{\circ} \mathrm{C}$ overnight The final wash conditions were 20 min at $42^{\circ} \mathrm{C}$ in $0.1 \times$ SSC. Inserts from positive clones were subcloned into pGEM7 (Promega) and sequenced by a dideoxy termination method.

The human $b c / x_{S}$ was cloned from a thymic cDNA library using a BamHI-Sphl fragment of the chicken bol-x under the hybridization and washing conditions described above. The insert was then amplified from the plaque-purified phage by PCR using $\lambda$ gt11 primers with $X$ bal linker sites and pfu polymerase. The $0.84 \mathrm{~kb}$ amplified fragment was then subcloned into pBluescript $S K(+)$ (Stratagene) for sequence analysis.

To clone the $b c l-x_{L}$ CDNA and to recione the $b c t-x_{S}$ CDNA into a form to be used in functional analysis, PCR primers corresponding to sequences in the $5^{\prime}$ untranslated region ( $5^{\prime}$-TTGGACAATGGACTGGTTGA-3) and the $3^{\prime}$ untranslated region (5'-GTAGAGTGGATGGTCAGTG-3) of the $b c / x_{S}$ cDNA were synthesized. The primers contained EcoRI linkers for subcloning and were used to amplify clones from cDNA libraries prepared from human T cells, the T cell line Jurkat and human brain. The phage $\left(10^{7} \mathrm{pfu}\right)$ was boiled for $5 \mathrm{~min}$ in $25 \mu \mathrm{l}$ of water prior to the PCRs $\left(1.25 \mathrm{~min}\right.$ at $94^{\circ} \mathrm{C}, 2 \mathrm{~min}$ at $56^{\circ} \mathrm{C}, 3 \mathrm{~min}$ at $72^{\circ} \mathrm{C} \times 35$ cycles). Bands of appropriate size $\left(0.8 \mathrm{~kb}\right.$ for $b c-x_{L}$ and $0.6 \mathrm{~kb}$ for $\left.b c \mathrm{-}-x_{s}\right)$ that could hybridize to the $b c /-x_{s}$ cDNA were subcloned into the EcoRl site of pBluescript $S K(+)$ for sequence analysis and production of in vitro transcription and translation products. For trans fection and subsequent functional assays, the $b c /-x_{L}$ and $b c l-x_{S}$ inserts were excised from pBluescript $S K(+)$ and subcloned into the EcoRl site of pSFFV-Neo (Neo; Fuhlbrigge et al., 1988). Orientation of the inserts was determined by restriction enzyme mapping and plasmids with inserts in the forward orientation were designated PSFFV-Neo-

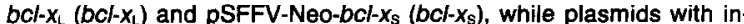
serts in the reverse orientation were named pSFFV-Neo-bcl- $x_{L}$ rev (bc)$x_{\llcorner}$rev) and pSFFV-Neo-bcl- $x_{S} r e v\left(b c /-x_{S} r e v\right)$.

Sequence comparisons and peptide analyses were performed with the University of Wisconsin Genetics Computer Group programs: FASTA, TFASTA, PILEUP, PEPTIDESTRUCTURE, and GAP

\section{Southern Blot Analysis}

Genomic DNA from chicken, mouse, and human lymphoid cells was isolated by standard methods, as previously described (Thompson and Neiman, 1987). The DNA was quantitated, and $10 \mu \mathrm{g}$ was digested with the indicated restriction enzymes overnight. Digested DNA was separated on a $1 \%$ agarose gel and blotted onto nitrocellulose. Blots were hybridized as described above with either an Sphl-BamHI fragment of chicken bcl-x or a HindIII-BamHI fragment from the first coding exon of mouse bcl-2. Washing conditions were as described above.

\section{Cell Isolation and RNA Analysis}

For the chicken tissue Northern blots, newly hatched chicks were sacrificed, and RNA was isolated from the indicated tissues by a guanidinium isothiocyanate method followed by centrifugation through a cesium chloride gradient as previously described (Thompson et al., 1986). RNA was equalized to the $28 \mathrm{~S}$ ribosomal RNA, separated on agarose-formaldehyde gels, and subsequently blotted onto nitrocellulose. The blots were probed with the Sphl-BamHI chicken bcl-x fragment. Blots were then stripped by boiling and hybridized with the HindlII-BamHI mouse bc/-2 probe.

Human T cells were isolated from healthy donors by leukophoresis followed by density gradient centrifugation. CD28-positive $T$ cells were negatively selected via an immunomagnetic procedure (June et al. 1987). RNA was then isolated from T cells that were either resting or activated with PMA $(10 \mathrm{ng} / \mathrm{ml})$ and ionomycin $(0.8 \mu \mathrm{g} / \mathrm{ml})$ for the indicated times. RNA was equalized and subjected to electrophoresis through agarose-formaldehyde denaturing gels, and the gels were then blotted as described above. Duplicate blots were probed with the human $b c l-x_{S}$ cDNA or the mouse $b c /-2$ exon II fragment and a human leukocyte antigen class I cDNA. Final washing conditions were $0.1 \times$ SSC, $0.1 \%$ SDS for $20 \mathrm{~min}$ at $56^{\circ} \mathrm{C}$

Human thymocytes were isolated from surgical pathology specimens from children under the age of 3 years who had undergone cardiothoracic surgery. Thymic tissue was passed through nylon mesh to obtain a single cell suspension, followed by separation of mononuclear cells on a Ficoll-Hypaque cushion. ANA was then extracted from either resting or PMA and ionomycin-stimulated cells and subjected to Northern blot analysis. To determine whether $b c l-x$ expression was regulated during thymocyte development, thymocytes were separated into mature (single-positive cells) and immature (double-positive cells) subpopulations prior to stimulation and RNA extraction as previously described (Turka et al., 1991). In brief, thymocyte fractionation was performed by negative immunomagnetic selection. Immature thymocytes were prepared by removal of cells expressing high levels of CD28, while mature thymocytes were selected by the removal of $C D 1^{+}$ cells. The expression status of the resulting cells for CD4 and CD8 confirmed that more than $90 \%$ of the immature population expressed CD4 and CD8 while more than $95 \%$ of the mature population were single-positive cells.

To determine which form of bcl-x mRNA was being expressed, $1 \mu \mathrm{g}$ of total cellular RNA or $0.1 \mu \mathrm{g}$ of poly $(\mathrm{A})^{+}$RNA from the various sources was reverse transcribed with avian myeloblastosis virus reverse transcriptase for $1 \mathrm{hr}$ at $42^{\circ} \mathrm{C}$. Twenty percent of the cDNA product was then subjected to PCR using the $5^{\prime}$ and $3^{\prime}$ primers and amplification conditions described above. Because the two primers are each located on separate coding exons, the amplification product of contaminating genomic DNA will be much larger than the product of either of the two RNA species, $b c l-x_{\mathrm{L}}$ and $b c l-x_{\mathrm{S}}$. To assure that the PCR conditions were not biased to one form of the cDNA, concurrent $P C R s$ were run with plasmids containing $b c l-x_{L}$ or $b c l-x_{S}$ alone or mixed in various ratios.

\section{Cell Transfection and Functional Studies}

Murine FL5.12 cells were cultured as previously described (Hockenbery et al., 1990; Nuñez et al., 1990). Cells were transfected by electroporation $(200 \mathrm{~V}, 960 \mu \mathrm{F})$ with the pSFFV-Neo plasmid containing either $b c /-2_{\alpha}(b c /-2), b c /-x_{\llcorner}$in both transcriptional orientations (bcl- $x_{\llcorner}$and $b c /-$ $x_{L}$ rev), or $b c l-x_{S}$ in both transcriptional orientations (bcl- $x_{S}$ and bcl$x_{s}$ rev). As a control, transfections were also performed with the pSFFV. Neo plasmid without an insert (Neo). Transfectants were selected for the acquisition of neomycin resistance by growth in the presence of G418 (1 mg/ml). Bulk transfectants and single cell clones (generated 
by limiting dilution) were maintained by growth in media supplemented with IL-3 as previously described (Nuñez et al., 1990). To assess cell survival, cells were first grown at $2 \times 10^{5}$ cells per $\mathrm{ml}$ in the presence of an optimal concentration of growth factor for 20-24 hr. The cells were then washed with RPMI 1640 medium three times to remove any residual IL-3 and plated at $10^{5}$ cells per well in 96-well culture dishes in medium supplemented with $10 \%$ fetal calf serum. Cell survival was determined at the indicated time points by trypan blue exclusion. To confirm that cell death was due to apoptosis, transfected cells $\left(2 \times 10^{8}\right)$ were isolated $0,8,24$, and $48 \mathrm{hr}$ after growth factor removal and lysed in $1.0 \%$ SDS, $100 \mathrm{mM} \mathrm{NaCl}, 10 \mathrm{mM}$ Tris (pH 8.0), $1 \mathrm{mM}$ EDTA, and $200 \mu \mathrm{g} / \mathrm{ml}$ proteinase $\mathrm{K}$ for $2 \mathrm{hr}$ at $50^{\circ} \mathrm{C}$. Following incubation, samples were treated with RNAase A $(20 \mu \mathrm{g} / \mathrm{ml})$ for $2 \mathrm{hr}$ at $37^{\circ} \mathrm{C}$ phenol-chloroform extracted, and ethanol precipitated. DNA was then separated on a $1.2 \%$ agarose gel and stained with ethidium bromide.

To determine Bcl-2 expression, cells were washed and fixed with $1 \%$ paraformaldehyde for $10 \mathrm{~min}$ at room temperature. Cells were then stained with the $6 \mathrm{CB}$ monoclonal antibody, a hamster monocional antibody specific for human Bcl-2 (Hockenbery et al., 1990), or an isotype-matched hamster antibody control in $0.3 \%$ saponin in phosphate-buffered saline for $30 \mathrm{~min}$ at $4^{\circ} \mathrm{C}$. Cells were washed in $0.03 \%$ saponin-phosphate-buffered saline and incubated with biotinylated $F\left(a b_{2}^{\prime}\right)$ goat anti-hamster immunoglobulin $G$ for $30 \mathrm{~min}$ at $4^{\circ} \mathrm{C}$. Cells were washed in $0.03 \%$ saponin-phosphate-buffered saline, incubated with RED 670-streptavidin, and analyzed by flow cytometry. Analysis of $b c l-x_{L}-$ and bcl- $x_{S}-$ transfected cells revealed that the Bcl-2-specific antibody did not crossreact with the $\mathrm{Bcl}-\mathrm{x}$ expressed in these cells. bCl-x expression was confirmed by Northern blot analysis, with $\beta$-actin expression utilized as a loading control.

\section{In Vitro Transcription and Translation of bcl-x}

pBluescript $S K(+)$ plasmids containing $b c l-x_{L}$ and $b c l-x_{s}$ were linearized at the $3^{\prime}$ multiple cloning site with $\mathrm{Xbal}$ and $\mathrm{BamHI}$, respectively, and transcribed with $\mathrm{T7}$ RNA polymerase for $1 \mathrm{hr}$ at $37^{\circ} \mathrm{C} . \mathrm{bcl}-\mathrm{x}_{\llcorner}$was also linearized at the $5^{\prime}$ multiple cloning site with $X$ hol and transcribed with T3 polymerase as an antisense control. The resulting runoff transcripts ( $b c l-x_{L}, b c l-x_{s}$, and $b c l-x_{S}-a s$ ) were phenol-chloroform extracted and ethanol precipitated. In vitro translation was then performed with a rabbit reticulocyte lysate kit (Promega) in the presence of ${ }^{35}$ S]methionine for $1 \mathrm{hr}$ at $30^{\circ} \mathrm{C}$. Lysate $(5 \mu \mathrm{ll})$ was added to SDS loading buffer and subjected to SDS-polyacrylarnide gel electrophoresis ( $15 \%$ gel). Gels were dried and exposed to X-ray film.

\section{Acknowledgments}

The authors would like to thank Haidi Yang for technical assistance We are grateful to Stan Korsmeyer for the communication of unpublished results; to Jeff Leiden, Harinder Singh, Lou Laimins, Susan Lindquist, Emma Masteller, Stacy Ferguson, David Katz, Jonathan Green, and Charlie Rudin for many thoughtful discussions and critica reviews of this work; and to Jeanelle Pickett and Beverly Prenevost for their assistance in the preparation of the figures. This work was supported in part by grants from the US Public Health Service (P60AF20557 to G. N.) and the Horace H. Rackham School of Graduate Study (to G. N.). M. G.-G. was supported by a fellowship from the North Atlantic Treaty Organization.

Received May 26, 1993; revised June 28, 1993

\section{References}

Allsopp, T. E., Wyatt, S., Paterson, H. F., and Davies, A. M. (1993) The proto-oncogene bcl-2 can selectively rescue neurotrophic factordependent neurons from apoptosis. Cell 73, 295-307.

Bakhshi, A., Jensen, J. P., Goldman, P., Wright, J. J., McBride, O. W. Epstein, A. L., and Korsmeyer, S. J. (1985). Cloning the chromosomal breakpoint of $t(14 ; 18)$ human lymphomas: clustering around $J_{H}$ on chromosome 14 and near a transcriptional unit of 18 . Cell 41,899 906.

Blackman, M., Kappler, J., and Marrack, P. (1990). The role of the T cell receptor in positive and negative selection of developing T cells. Science 248, 1335-1341.

Borzillo, G. V., Endo, K., and Tsujimoto, Y. (1992). Bcl-2 confers growth and survival advantage to interleukin 7-dependent early pre-B celis which become factor independent by a multistep process in culture. Oncogene 7, 869-876.

Cazals-Hatem, D. L., Louie, D. C., Tanaka, S., and Reed, J. C. (1992). Molecular cloning and DNA sequence analysis of cDNA encoding chicken homologue of the Bcl-2 oncoprotein. Biochim. Biophys. Acta 1132, 109-113.

Chen-Levy, Z., and Cleary, M. L. (1990). Membrane topology of the Bcl-2 proto-oncogenic protein demonstrated in vitro. J. Biol. Chem. $265,4929-4933$.

Chen-Levy, Z., Nourse, J., and Cleary, M. L. (1989). The bcl-2 candidate proto-oncogene product is a 24-kilodalton integral-membrane protein highly expressed in lymphoid cell lines and lymphomas carrying the $t(14 ; 18)$ translocation. Mol. Cell. Biol. 9, 701-710.

Chleq-Deschamps, C. M., LeBrun, D. P., Huie, P., Besnier, D. P., Warnke, R. A., Sibley, R. K., and Clearly, M. L. (1993). Topographical dissociation of BCL-2 messenger RNA and protein expression in human lymphoid tissues. Blood 81, 293-298.

Cleary, M. L., Smith, S. D., and Sklar, J. (1986). Cloning and structural analysis of cDNAs for $b c /-2$ and a hybrid $b c t-2 /$ immunoglobulin transcript resulting from the $t(14 ; 18)$ translocation. Cell $47,19-28$.

Cooper, M. D., Chen, C.-L. H., Bucy, R. P., and Thompson, C. B. (1991). Avian T cell ontogeny. Adv. Immunol. 50, 87-117.

Cowan, W. M., Fawcett, J. W., O'Leary, D. D. M., and Stanfield, B. B. (1984). Regressive events in neurogenesis. Science 225, 12581265.

Cuende, E., Ales-Martinez, J. E., Ding, L., Gonzalez-Garcia, M., Martinez-A., C., and Nuñez, G. (1993). Programmed cell death by bcl-2dependent and independent mechanisms in B lymphoma cells. EMBO J. 12, 1555-1560

Davies, A. M. (1987). Molecular and cellular aspects of patterning sensory neurone connections in the vertebrate nervous system. Development 101, 185-208.

Eguchi, Y., Ewert, D. L., and Tsujimoto, Y. (1992). Isolation and characterization of the chicken bcl-2 gene: expression in a variety of tissues including lymphoid and neuronal organs in adult and embryo. Nucl. Acids Res. 20, 4187-4192.

Ellis, R. E., Yuan, J., and Horvitz, H. R. (1991). Mechanisms and functions of cell death. Annu. Rev. Cell Biol. 7, 663-698.

Fuhlbrigge, R. C., Fine, S. M., Unanue, E. R., and Chaplin, D. D. (1988) Expression of membrane interleukin 1 by fibroblasts transfected with pro-interleukin 1a. Proc. Natl. Acad. Sci. USA 85, 5649-5653.

Garcia, I., Martinou, I., Tsujimoto, Y., and Martinou, J.-C. (1992). Prevention of programmed cell death of sympathetic neurons by the $\mathrm{bcl}-2$ proto-oncogene. Science 258, 302-304.

Graninger, W. B., Seto, M., Boutain, B., Goldman, P., and Korsmeyer, S. J. (1987). Expression of BCl-2 and BCl-2-lg fusion transcripts in normal and neoplastic cells. J. Clin. Invest. 80, 1512-1515.

Hockenbery, D., Nuñez, G., Milliman, C., Schreiber, R. D., and Korsmeyer, S. J. (1990). Bcl-2 is an inner mitochondrial membrane protein that blocks programmed cell death. Nature 348, 334-336.

June, C. H., Ledbetter, J. A., Gillespie, M. M., Lindsten, T., and Thompson, C. B. (1987). T-cell proliferation involving the CD28 pathway is associated with cyclosporin-resistant interleukin 2 gene expression. Mol. Cell. Biol. 7, 4472-4481.

Kawabe, Y., and Ochi, A. (1991). Programmed cell death and extrathymic reduction of $\mathrm{V}_{B} 8^{+} \mathrm{CD} 4^{+} \mathrm{T}$ cells in mice tolerant to Staphylococcus aureus enterotoxin B. Nature 349, 245-248.

Kerr, J. F. R., Wyllie, A. H., and Currie, A. R. (1972). Apoptosis: a basic biological phenomenon with wide-ranging implications in tissue kinetics. Br. J. Cancer 26, 239-257.

McDonnell, T. J., Deane, N., Platt, F. M., Nunez, G., Jaeger, U., McKearn, J. P., and Korsemeyer, S. J. (1989). bcl-2-immunoglobulin transgenic mice demonstrate extended $B$ cell survival and follicular 
Murphy, K. M., Heimberger, A. B., and Loh, D. Y. (1990). Induction by antigen of intrathymic apoptosis of $\mathrm{CD4}^{+} \mathrm{CDB}^{+} T \mathrm{TR}^{\circ}$ thymocytes in vivo. Science 250, 1720-1723.

Negrini, M., Silini, E., Kozak, C., Tsujimoto, Y., and Croce, C. M. (1987). Molecular analysis of mbcl-2: structure and expression of the murine gene homologous to the human gene involved in follicular lymphoma. Cell 49, 465-463.

Neiman, P. E., Thomas, S. J., and Loring, G. (1991). Induction of apoptosis during normal and neoplastic B-cell development in the bursa of Fabricius. Proc. Natl. Acad. Sci. USA 88, 5857-5861.

Nuñez, G., London, L., Hockenbery, D., Alexander, M., McKearn, J. P., and Korsmeyer, S. J. (1990). Deregulated Bcl-2 gene expression selectively prolongs survival of growth factor-deprived hematopoietic cell lines. J. Immunol. 144, 3602-3610.

Oppenheim, R. W. (1991). Cell death during development of the nervous system. Annu. Rev. Neurosci. 14, 453-501.

Raff, M. C. (1992). Social controls on cell survival and cell death. Nature 356, 397-400.

Reed, J. C., Tsujimoto, Y., Alpers, J. D., Croce, C. M., and Nowell, P. C. (1987). Regulation of bCl-2 proto-oncogene expression during normal human lymphocyte proliferation. Science 236, 1295-1299.

Rothenberg. E. V. (1992). The development of functionally responsive T cells. Adv. Immunol. 51, 85-214.

Sentman, C. L., Shutter, J. R., Hockenbery, D., Kanagawa, O., and Korsmeyer, S. J. (1991). bcl-2 inhibits multiple forms of apoptosis but not negative selection in thymocytes. Cell 67, 879-888.

Siegel, R. M., Katsumata, M., Miyashita, T., Louie, D. C., Greene, M. I., and Reed, J. C. (1992). Inhibition of thymocyte apoptosis and negative antigenic selection in bcl-2 transgenic mice. Proc. Natl. Acad. Sci. USA 89, 7003-7007.

Strasser, A., Harris, A. W., and Cory, S. (1991a). bcl-2 transgene inhibits $T$ cell death and perturbs thymic self-censorship. Cell 67, 889-899.

Strasser, A., Whittingham, S., Vaux, D. L., Bath, M. L., Adams, J. M., Cory, S., and Harris, A. W. (1991b). Enforced BCL2 expression in $B$-lymphoid cells prolongs antibody responses and elicits autoimmune disease. Proc. Natl. Acad. Sci. USA 88, 8661-8665.

Thompson, C. B., and Neiman, P. E. (1987). Somatic diversification of the chicken immunoglobulin light chain is limited to the rearranged variable gene segment. Cell 48, 369-378.

Thompson, C. B., Challoner, P. B., Neiman, P. E., and Groudine, $M$. (1986). Expression of the c-myb proto-oncogene during cellular proliferation. Nature 319, 374-380.

Tsujimoto, Y., and Croce, C. M. (1986). Analysis of the structure, transcripts, and protein products of bcl-2, the gene involved in human follicular lymphoma. Proc. Natl. Acad. Sci. USA 83, 5214-5218.

Turka, L. A., Linsley, P. S., Paine, R., III, Schieven, G. L., Thompson, C. B., and Ledbetter, J. A. (1991). Signal transduction via CD4, CD8, and $\mathrm{CD} 28$ in mature and immature thymocytes. J. Immunol. 146, 1428-1436.

Vaux, D. L., Cory, S., and Adams, J. M. (1988). Bcl-2 gene promotes haemopoietic cell survival and cooperates with c-myc to immortalize pre-B cells. Nature $335,440-442$.

Webb, S. Morris, C., and Sprent, J. (1990). Extrathymic tolerance of mature $T$ cells: clonal elimination as a consequence of immunity. Cell $63,1249-1256$.

Williams, G. T. (1991). Programmed cell death: apoptosis and oncogenesis. Cell 65, 1097-1098.

Wyllie, A. H., Kerr, J. F. R., and Currie, A. R. (1980). Cell death: the significance of apoptosis. Int. Rev. Cytol. 68, 251-306.

\section{GenBank Accession Numbers}

The accession numbers of the sequences reported in this paper of chicken bcl-x, human bol- $\mathrm{L}_{\mathrm{L}}$, and human $b c \mathrm{l}-\mathrm{x}_{\mathrm{S}}$ are L20120, L20121. and L20122, respectively. 